\title{
Instituições do Estado e políticas de regulação e incentivo ao cinema no Brasil: o caso Ancine e Ancinav*
}

\author{
Fabio Kobol Fornazari**
}

SuMÁRIO: 1. Introdução; 2. Reforma do Estado e agências reguladoras; 3. Estado e cinema; 4. Descrevendo e analisando a Ancine; 5. Ancinav; 6. A polêmica; 7. Analisando experiências estrangeiras; 8 . Conclusões.

S UMMARY: 1. Introduction; 2 . State reform and regulatory agencies; 3. State and cinema; 4. Describing and analyzing Ancine; 5. Ancinav; 6. The controversy; 7. Analyzing foreign experiences; 8. Conclusions.

PAlavRas-chave: reforma do Estado; agência reguladora; políticas públicas; cultura; audiovisual; cinema.

KEY WORDS: State reform; regulatory agency; public policies; culture; audiovisual industry; film industry.

Este artigo analisa as políticas públicas de regulação, fiscalização e incentivo à indústria audiovisual no Brasil, a partir da criação da Agência Nacional do Cinema (Ancine). Pela perspectiva das transformações recentes no aparato institucional do Estado brasileiro, o artigo estuda a especificidade de uma agência reguladora criada para atuar nesse setor de política pública. Analisa o panorama histórico da relação entre Estado e cinema no Brasil, bem como os resultados concretos e o significado estratégico da atuação da agência, e compara os modelos institucionais de regulação do setor em outros países selecionados: Argentina, México, França e Reino Unido. Além disso, avalia o debate sobre a mudança no perfil e escopo da agência, com sua possível

\footnotetext{
* Artigo recebido em fev. e aceito em maio 2006.

** Cientista social e mestrando em administração pública e governo pela Eaesp/FGV. Professor na Universidade Metodista e analista de cultura na Prefeitura de São Bernardo do Campo. Endereço: Rua Jurubatuba, 1086, ap. 46 - CEP 09725-220, São Bernardo do Campo, SP, Brasil. E-mail: fkcine@directnet.com.br.
} 
substituição pela Agência Nacional do Cinema e do Audiovisual (Ancinav) e a forma polêmica pela qual esta proposta foi recebida pela comunidade cultural e cinematográfica. Finalmente, o artigo interpreta o que constitui, nessa experiência brasileira, um aparato institucional a que dá o nome de "agência articuladora de política pública setorial".

\section{State institutions and regulation and support policies for the film industry in Brazil: the case of Ancine and Acinav}

This article analyzes the regulation, overseeing and support policies for the audiovisual industry in Brazil, since the creation of the National Film Agency (Ancine). From the perspective of the recent changes in the institutional apparatus of the Brazilian state, the article studies the specificity of a regulatory agency created for this public policy sector. It analyzes the historical background of the relationship between state and film industry in Brazil, as well as the concrete results and strategical meaning of the agency's actions, and compares regulatory institution models in other selected countries: Argentina, Mexico, France and UK. It also discusses the debate on the agency's change of profile and scope, with its possible substitution by The National Film and Audiovisual Agency and the controversy this proposal raised in the cultural and film community. Finally, the article interprets what constitutes, in this Brazilian experience, the institutional apparatus that it calls 'sectorial public policy articulation agency'.

\section{Introdução}

Esta pesquisa qualitativa descreve e analisa, numa perspectiva histórica e comparativa, as atuais políticas públicas de regulação e fomento ao cinema, organizadas sobre o desenho institucional de uma agência reguladora independente. Além disso, estuda as diferenças, avanços e recuos entre os modelos de órgãos federais brasileiros de regulação do audiovisual, do cinema e da comunicação, antes e após a criação da agência, descrevendo suas atribuições, gênese e resultados. Procura, também, discernir as possíveis conseqüências culturais e econômicas que a mudança para o modelo proposto para a criação da Ancinav podem provocar, pelo estudo comparativo de seus textos legais. Da mesma forma, estudaremos casos específicos de relação entre estruturas de Estado e políticas para o cinema, analisando países com semelhanças históricas e econômicas com o Brasil: Argentina e México; a França, considerada pela literatura o caso extremo de posicionamento estratégico do Estado em termos de regulação cultural, fomento ao cinema e defesa de identidade nacional; e o Reino Unido, modelo de "agencificação" da esfera pública. 
A análise teórica desta pesquisa se insere no contexto mais amplo das reformas gerenciais e institucionais ocorridas no setor público nas últimas décadas, em especial pela crescente recorrência à criação de agências reguladoras independentes. Nesse sentido, é necessário refletir sobre as razões e objetivos que levam o Estado brasileiro a criar tal mecanismo institucional para fiscalização e fomento de uma área de atividade, o cinema, que não é objeto tradicional de políticas de regulação por agências independentes.

Normalmente criadas após concessões de serviços essenciais ou privatizações de empresas públicas, ou, ainda, quebras de monopólios estatais, as agências reguladoras vincularam-se, numa primeira fase, à dimensão reguladora e fiscalizadora de serviços de cunho econômico e da infra-estrutura. A criação das agências é justificada pela literatura pelo seu intuito de atrair e regular investimentos, reduzir arbitrariedades do setor público, defender o consumidor e o interesse coletivo, fixar preços e tarifas, aumentar a flexibilidade de gestão e normatização, insular a burocracia especializada das incertezas políticas, aumentar o controle social e, principalmente, oferecer credibilidade aos investidores privados. Os mecanismos de autonomia e estabilidade, que lhe são intrínsecos, reduzem o risco do investimento, mormente em atividades em que os montantes de investimento requerido são altos e a maturação da inversão de capital é de longo prazo - sunk costs e escolhas intertemporais (Melo, 2001).

No caso da Ancine, pergunta-se qual o sentido e a justificativa da criação de tal mecanismo institucional para regular a atividade cinematográfica e, além disso, quais os interesses econômicos e sociais que lhe são subjacentes.

É sabido que nos países em desenvolvimento, como o Brasil, a diminuta poupança privada requer a intervenção do poder público como fomentador e financiador de atividades que necessitam de altos investimentos. A intervenção ocorre, especialmente, quando os interesses econômicos envolvidos possuem forte penetração social e papel relevante na formação da opinião pública.

Entre as agências criadas, o caso da Ancine é bastante peculiar, inclusive em perspectiva comparativa com experiências internacionais. Definida como "órgão de fomento, regulação e fiscalização da indústria cinematográfica e videofonográfica", que busca "aumentar a competitividade da indústria por meio do fomento à produção, distribuição e exibição da produção nacional nos diversos segmentos de mercado" (Brasil, 2001). A agência, entre suas competências, "atribuições que parecem caracterizar a atividade de fomento, mais do que regulação, não se justificando, portanto, o formato adotado de agência reguladora" (Pacheco, 2004).

No caso do cinema, o investimento direto por meio de mecanismos geridos pela empresa estatal Embrafilme, extinta em 1990, alçavam o Estado à condição de socioprodutor da indústria cinematográfica. Na ausência desse suporte, 
e sem outras alternativas públicas, o setor definhou por cerca de quatro anos, até que mecanismos de incentivo baseados em renúncia fiscal viessem a suprir a necessidade de investimento público no setor audiovisual. O modelo de lei de incentivo e de agência reguladora é expressão e exemplificação dos novos paradigmas de ação do Estado e de sua relação com a sociedade.

O poder público, assim, não se desloca totalmente da intervenção no domínio econômico e social, pois precisa preencher as imperfeições de um mercado relativamente de pequena escala, com limitações tecnológicas e sem acesso viável a financiamentos privados. Além disso, vive-se uma configuração de mercado em que há a hegemonia da produção cinematográfica de origem norte-americana de um lado e, de outro, uma importante e influente camada de indivíduos e organizações nacionais exercendo pressão por apoio e recursos para o setor. São, em geral, formadoras de opinião com acesso à mídia, ou mesmo as próprias empresas de comunicação social e grandes companhias produtoras da indústria de entretenimento, que possuem fortes canais de poder para pressionar por auxílio oficial.

\section{A opção pela agência reguladora}

Esta pesquisa descreve a gênese histórica do pensamento que definiu a constituição, no Brasil, de uma agência reguladora independente como a Ancine, e de como o processo de intervenção oficial no domínio econômico e cultural age efetivamente em relação aos setores em que atua, tomando-se como exemplo as políticas públicas de cultura e cinema.

O Estado brasileiro recupera, a partir de meados dos anos 1990, tanto o sentido da importância social, política e econômica da produção cinematográfica - tomando-a como estratégica para a conformação da identidade cultural nacional - quanto a noção de setor industrial a ser fomentado e protegido pelo Estado. Há, além disso, a necessidade de aumentar a competitividade nacional para a inserção na economia globalizada, atraindo novos investimentos para um setor em expansão (Farias, 2002). A resposta, em termos de construção institucional, se dá pela adaptação, com características de difusão e isomorfismo (Gilardi, 2003). Ocorre a substituição de estruturas anteriormente existentes - ou mesmo a não-existência de quaisquer mecanismos institucionais - pelo modelo de agência reguladora independente, em franca expansão dentro da máquina estatal.

Criada sob a égide do Ministério do Desenvolvimento, Indústria e Comércio, a Ancine permanece sob a supervisão da Casa Civil para, em 2003, passar finalmente para o âmbito do Ministério da Cultura. Esse percurso exemplifica, 
involuntariamente, a especificidade de seu objeto. O setor cinematográfico, criado em decorrência da aproximação da arte com o desenvolvimento tecnológico, encerra em si mesmo a ambigüidade de ser uma atividade industrial — que requer alto investimento e retorno a longo prazo — e, também, um fenômeno estético, cultural e artístico, que acarreta na vida contemporânea dos países uma ampla força simbólica em termos de construção e promoção da identidade cultural nacional.

Por outro lado, essa análise se insere ainda em outros tópicos de importância teórica, sob o prisma da pesquisa em ciências sociais: o conceito teórico de "exceção cultural" (Casella, 2002), originário da França, e atualmente propagado internacionalmente, pelo qual políticas de promoção da identidade cultural passam a ser consideradas estratégicas do ponto de vista nacional, o que nos leva a refletir se cabe ao Estado regular política cultural e a forma de fazê-lo; o grau de intervenção do Estado contemporâneo em políticas públicas de cultura e sua interação com a sociedade e setores produtores; e como descrever a Ancine em termos comparativos e de resultados efetivamente alcançados, no período de 2002 a 2004.

Em resumo, pretende-se responder qual o significado, para o estudo comparado de políticas públicas, da existência de uma agência reguladora na área cultural e sua atuação em termos de fiscalização, financiamento e fomento do setor audiovisual, buscando responder às seguintes questões: por que uma agência reguladora para a área do audiovisual? A fiscalização e o fomento justificam a agência reguladora? Qual a especificidade dos modelos Ancine e Ancinav em termos institucionais? Quais os padrões de aproximação e distanciamento com outras experiências internacionais na área?

\section{Estrutura da pesquisa e do artigo}

Analisamos a criação de agências reguladoras no bojo das transformações recentes do Estado brasileiro. Descrevemos historicamente a relação entre Estado e cinema no Brasil, analisando as transformações institucionais contemporâneas que moldaram o surgimento de agências reguladoras independentes e sua relação específica com a área de cinema. Analisamos, comparativamente, os textos legais de criação da Ancine e o pré-projeto de criação da Ancinav, além do estudo de legislação pertinente ao assunto, avaliando, retrospectivamente, o impacto da Ancine em termos de realização dos objetivos de uma política nacional de cinema e dos resultados concretos alcançados em sua atuação no período de 2002 a 2004. Avaliamos, projetivamente, as mudanças a serem implantadas com a criação da Ancinav e seus possíveis resultados em termos de políticas públicas de promoção da cultura nacional, interpretando a recente polêmica que envolveu os defenso- 
res e os detratores da criação da Ancinav num debate ideologicamente polarizado. Comparamos algumas experiências internacionais relativas ao tema do artigo, que possam contribuir ao entendimento do caso brasileiro. Aqui, estudaremos Argentina, México, França e Reino Unido. Concluímos pela aplicação do conceito de "agência articuladora de política pública setorial".

\section{Metodologia}

Esta pesquisa tem caráter descritivo, analítico e qualitativo. Para isso, são utilizados os procedimentos a seguir.

\section{Revisão bibliográfica}

- Estudo da legislação brasileira referente ao tema das agências reguladoras de cinema.

- Estudo da legislação de experiências internacionais: Argentina, México, França e Reino Unido.

- Análise da teoria sobre a reforma contemporânea do Estado, a criação de agências reguladoras e seu impacto na execução de políticas públicas.

- Análise da teoria sobre a relação entre Estado e cinema no Brasil.

\section{Descrição e análise qualitativa de bases de comparação de textos} legais nacionais e estrangeiros

- Pesquisa de documentos, artigos, reportagens, entrevistas e manifestos alusivos à recente polêmica sobre a substituição da Ancine pela Ancinav.

- Análise qualitativa dos dados referentes à produção cinematográfica após a criação da Ancine.

\ Análise final, sistematização e conclusão.

\section{Reforma do Estado e agências reguladoras}

A análise das recentes reformas do Estado brasileiro, com a mudança de seu perfil institucional, está relacionada à revolução tecnológica e informacional e à 
busca de fontes de investimento e capitais externos. Nesse sentido, a partir de meados dos anos 1990, buscou-se o redesenho e a reforma do Estado como garantia de governança, eficiência e credibilidade, associada à proposição de novos modelos de financiamento, organização e gestão do Estado. "A reforma do Estado deve ser entendida dentro do contexto da redefinição do papel do Estado, que deixa de ser o responsável direto pelo desenvolvimento econômico e social pela via da produção de bens e serviços, para fortalecer-se na função de promotor e regulador desse desenvolvimento" (Brasil/Mare, 1995). Mesmo renunciando à produção direta de bens e serviços, o Estado deve continuar mantendo atuação reguladora, dada a importância social e estratégica dos bens de natureza pública e devido às assimetrias de posições entre os atores que atuariam num mercado plenamente aberto (Oszlack, 1998). As agências passam a focalizar objetivos específicos, em contraposição à burocracia generalista do modelo anterior (Thatcher, 2002).

Assim, o Estado, na sua configuração atual, mesmo após renunciar à intervenção direta - o "Estado positivo", provedor direto de bens e serviços —, altera sua configuração institucional e seu paradigma de intervenção no domínio privado para o perfil conceituado de "Estado regulador" (Majone, 1999), modo de governança caracterizado pela elaboração normativa e delegação de poder. Em outras palavras, parte-se para um modelo de delegação, presumivelmente autônoma em relação a fatores políticos de curto prazo: "Das instituições novas destacam-se aquelas surgidas no esforço de institution-building pósreformas (...), as agências regulatórias independentes" (Melo, 2001).

De modo geral (Pacheco, 2004),

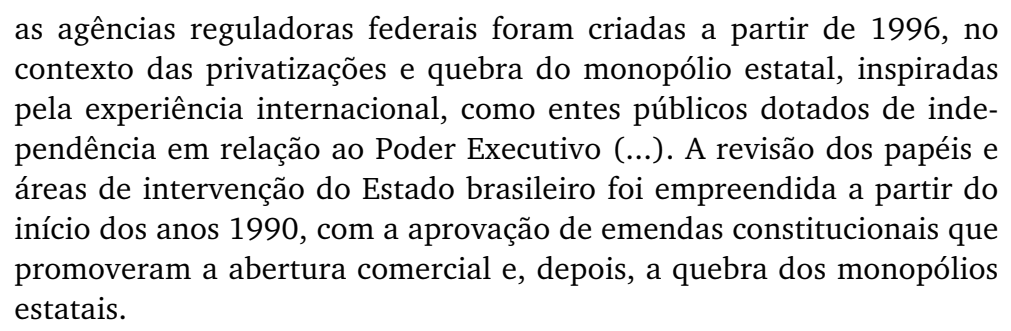

A literatura brasileira sobre regulação permite discutir, sobre uma base teórica segura, os modelos Ancine e Ancinav segundo parâmetros da história recente da reforma do Estado no Brasil. Pode-se, assim, analisar os discursos envolvidos na polêmica atual, segundo parâmetros que definem conceitualmente as agências, tais como autonomia, independência, publicidade e transpa- 
rência, mandatos fixos, agilidade, especialização técnica, credibilidade e eficácia. Por outro lado, verificamos as especificidades inerentes à criação da agência independente voltada ao cinema, área onde não houve quebra de monopólio, nem há necessidade premente de credibilidade regulatória para captação de investimentos ou insulamento de burocratas especialistas. Outros motivos, como o blame shifting - desincumbência de ações impopulares — ou a existência de monopólios naturais e imperfeições de mercados não-competitivos (Melo, 2000) também não a justificam.

Retomamos a tese de que a estrutura das agências já existentes foi indevidamente estendida às agências criadas subseqüentemente (Salgado, 2003) como difusão e isomorfismo institucional (Gilardi, 2003). Além disso, refletimos sobre como o interesse público direto se vê refletido na atuação e capacidade de implantar políticas públicas e normatizar e fiscalizar o setor, envolvido em uma teia de interesses heterogêneos, com graus diversos de hegemonia, visibilidade social e política e interesses econômicos.

Mesmo não havendo literatura específica sobre a Ancine, os quadros conceitual, teórico e bibliográfico ajudam a discutir a articulação entre a reforma do Estado e a criação das agências. Em resumo, como os instrumentos de um novo Estado reformado atendem a disputas de interesses consolidados historicamente, e qual a efetiva possibilidade de consolidação desses mecanismos institucionais em relação a políticas públicas assumidas pelo Estado brasileiro?

\section{Estado e cinema}

As relações entre a indústria do cinema e o poder público articulam historicamente questões como mercado, fomento, legislação, distribuição, formação de público, tecnologia e relações com o cinema internacional. Analisamos a economia do cinema e as políticas culturais a ela subjacentes através de um recorte que remete, também, ao estudo e descrição de políticas oficiais, das pressões de grupos de interesse, da conformação de instrumentos legais e aparelhos institucionais, e das escolhas que os diversos poderes estabelecidos formataram ao longo do século XX.

A descrição histórica da atuação do Estado no setor, nas últimas décadas, demonstra, de um lado, a extinção da Embrafilme e a hegemonia do pensamento neoliberal - Estado mínimo - questionando a intervenção estatal; de outro, a retomada da produção cinematográfica nos últimos anos, num contexto de adequação dos modos de produção à criação de leis de incentivo e de uma agência reguladora independente - a Ancine. A literatura sobre o tema permite traçar um painel das relações entre cinema e Estado no século passa- 
do, principalmente a partir da Revolução de 1930, o que nos leva a quadros comparativos da atuação institucional dentro de uma perspectiva histórica.

A relação entre os produtores cinematográficos e o poder remonta às origens do cinema no Brasil, mas, com a Revolução de 1930, os cineastas se organizam em associações e procuram fazer com que suas reivindicações de proteção e incentivo à indústria nacional sejam postas em prática como políticas oficiais (Simis, 1996). O interesse do Estado se estabelece, então, como atendimento a interesses corporativos, como conformação de proteção estratégica a um setor da indústria nacional, como propaganda política, ou, ainda, com intenções educativas e de difusão cultural.

O anseio de modernização do país, a partir de 1930, valorizou a idéia da construção de uma identidade nacional e de instrumentos de difusão cultural, abrindo um novo relacionamento do cinema com o poder. A intervenção acontece nos planos da produção, distribuição, importação e exibição, fazendo com que o cinema deixe de ser uma atividade apenas regulada por leis de mercado. O Estado passa a regular a atividade e cria uma "cultura" de fomento e proteção que permanece até nossos dias, incorporando interesses do setor aos planos de políticas públicas, num contexto em que as vantagens competitivas são avassaladoras em favor da produção estrangeira, principalmente a norte-americana.

A evolução histórica demonstra a teia de relações complexas e contraditórias nas interfaces entre o Estado e a produção cinematográfica no Brasil. Os vínculos que se estabeleceram entre a política cultural do Estado e o cinema se expressam tanto nos modos de produção da indústria, quanto no fenômeno propriamente estético e ideológico, expressos na atuação política dos cineastas e em seus filmes (Ramos, 1983). Fresnot (2004) explica que o cinema brasileiro nunca conseguiu

\footnotetext{
bases econômicas e jurídicas que permitissem a sua efetiva consolidação como atividade auto-sustentável (...). O cinema é uma das áreas da atividade produtiva que mais cedo se globalizou. A indústria americana conquistou ao longo do século passado, com a defesa de seus produtores (...), uma escala de produção e distribuição única na história. É isto que torna a permanência de um esforço produtor por parte de outros países difícil de sustentar, e essencialmente dependente da intervenção estatal direta ou mediada, mas sempre imprescindível.
}

A formação da burocracia e a formatação de desenhos institucionais, que mediarão a relação dos produtores com o Estado, remetem diretamente à relação dos aparelhos institucionais de apoio ao cinema e os resultados des- 
sas políticas públicas na produção das obras, nos ganhos econômicos e no jogo político entre os interesses envolvidos. Além disso, a análise histórica expõe os diversos discursos de legitimação em sua reivindicação por apoio financeiro oficial para o setor.

A área de políticas públicas de cultura é, por definição, uma área "social". Analisando a estrutura e funcionamento da Ancine, porém, verificamos que a agência cumpre um papel preponderantemente econômico. Sua atuação é a da promoção de investimentos e de desenvolvimento setorial de um ramo industrial e apenas tangencia objetivos e valores ligados à identidade cultural nacional.

Especificamente, a agência tem um papel de órgão gestor arrecadador e alocador de recursos públicos, visando o investimento no mercado audiovisual, e muito mais fortemente no cinema de longa-metragem, de forma a fomentá-lo e regulá-lo. O perfil da Ancine se coaduna mais à gestão da norma legal e de recursos para fomento do que à execução de diretrizes e planos estratégicos de valorização cultural nacional pela indústria da imagem ou, ainda, da defesa da identidade e da diversidade num mundo em que se corre o risco de caminhar para a padronização cultural global.

Esta análise sugere a reflexão sobre os graus de intervenção e, principalmente, sobre o desenho institucional e legal mais bem adaptado às ações de fomento e ao montante de recursos que a sociedade está disposta a carrear, por meio do Estado, ao setor cinematográfico. Esperamos aportar subsídios qualitativos à reflexão sobre os resultados de políticas públicas de apoio à produção cinematográfica brasileira, na perspectiva contemporânea da agência reguladora independente que executa tais políticas.

\section{Descrevendo e analisando a Ancine}

A Agência Nacional de Cinema foi criada pela Medida Provisória nº 2.228-1, em 6 de setembro de 2001, como órgão oficial com a finalidade de promover o fomento, regulação e fiscalização das indústrias cinematográfica e videofonográfica (audiovisual). Dotada de autonomia financeira e administrativa, é uma agência reguladora independente na forma de autarquia especial. Sua concepção original previa vinculação ao Ministério do Desenvolvimento, Indústria e Comércio, mas o texto legal estabelecia sua permanência sob a supervisão da Casa Civil da Presidência por um ano, contado após a emissão da MP. Ali permaneceu, contudo, até outubro de 2003, quando finalmente foi transferida para o Ministério da Cultura.

Rap Rio de Janeiro 40(4):647-77, Jul./Ago. 2006 
A estrutura da agência tem como instância deliberativa máxima a diretoria colegiada, com mandatos fixos e não-coincidentes, composta por um diretorpresidente e três outros diretores, aprovados pelo Senado Federal em dezembro de 2001. O texto legal estabelece os seguintes objetivos para a Ancine: promover a cultura nacional e a língua portuguesa mediante a indústria cinematográfica e a integração das atividades governamentais ligadas ao setor; aumentar a competitividade por meio do fomento à produção, distribuição e exibição nos diversos segmentos do mercado; promover a auto-sustentabilidade do setor, visando o aumento da produção e da exibição de obras nacionais; promover a articulação da cadeia produtiva da indústria nacional; estimular a diversificação e o fortalecimento da produção independente e regional; estimular a universalização do acesso às obras, especialmente as nacionais; garantir a participação diversificada de obras estrangeiras no mercado brasileiro; estimular a participação de obras nacionais em todos os segmentos do mercado, inclusive no exterior; estimular a capacitação de recursos humanos e o desenvolvimento tecnológico; e zelar pelo respeito ao direito autoral.

Entre suas competências, destacam-se: executar a política nacional de fomento ao cinema; fiscalizar o cumprimento da legislação setorial; combater a falsificação de obras audiovisuais; regular, fomentar e proteger a indústria audiovisual nacional, resguardando a livre expressão e criação; coordenar as atividades governamentais relativas ao setor, articulando-se inclusive com outros entes federados; gerir programas e mecanismos de incentivo; promover a participação de obras brasileiras em festivais internacionais; controlar a produção realizada com recursos públicos e incentivos fiscais; fornecer certificados de produto brasileiro e gerir sistema setorial de informação; prestar apoio técnico e administrativo ao Conselho Superior do Cinema (nível ministerial); definir, fiscalizar e auferir a "cota de tela" para a produção nacional; autuar empresas, distribuidoras e exibidoras e locadoras pelo descumprimento de normas legais. A figura 1 mostra o organograma da estrutura administrativa da agência.

A agência está totalmente estruturada sobre um perfil de atuação econômica e de relação endógena com os interesses do setor. Não há previsão de estruturas mediadoras com os consumidores nem instâncias de planejamento qualitativo da intervenção cultural. Regula-se o cinema como atividade de cunho estritamente econômico, o que define a agência como uma gestora de fundos provenientes de renúncia fiscal, alocando-os como em qualquer outro segmento regulado de mercado, sem especificidade "social ou cultural".

$\mathrm{O}$ início efetivo das atividades da agência deu-se apenas em setembro de 2002, devido à demora na edição do decreto de regulamentação interna (4.121/02) e a restrições orçamentárias (Ancine, Relatório de gestão 2002; Brasil/TCU, 2004). Até este momento, a Ancine produziu três relatórios de gestão, referentes aos anos de 2002, 2003 e 2004. 
Figura 1

\section{Organograma da Ancine}

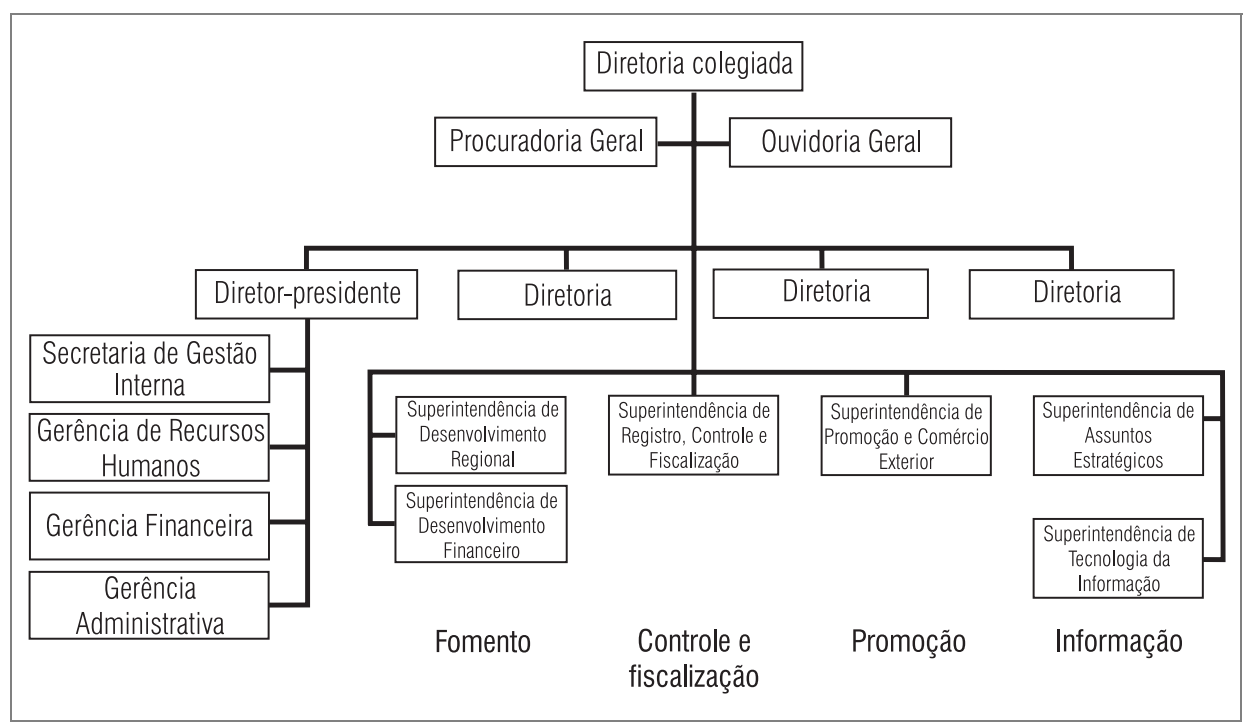

As atuações de fomento, compiladas pelo TCU, apresentam os mecanismos a seguir.

\section{Fomento direto}

Apoio financeiro à produção com recursos orçamentários próprios, mediante seleção e concursos públicos elaborados com base na Lei de Licitações (8.666/93).

\section{Fomento indireto}

Autorização e fiscalização dos projetos com recursos de renúncia fiscal, de acordo com os mecanismos a seguir.

\section{Lei no $8.313 / 91$ (Lei Rouanet)}

Permite que contribuintes abatam, do imposto de renda devido, doação ou patrocínio de projetos culturais. Podem ser abatidos 100\% para obras de cur- 
ta e média-metragem ou para festivais e projetos de difusão, ou 30\% (pessoa jurídica) e $60 \%$ (física) para patrocínio e projetos, ou $40 \%$ e $80 \%$, retrospectivamente, para doação a projetos de obras audiovisuais.

\section{Lei no $8.685 / 93$ (Lei do Audiovisual)}

Estabelece dois mecanismos de incentivo fiscal:

- certificados de investimento - permitem abater $100 \%$ dos recursos despendidos na compra de papéis de investimento, ou seja, direitos de comercialização de obras e de projetos de distribuição, exibição e infra-estrutura;

$\square$ investimento - permite às empresas que operam com obras estrangeiras no mercado brasileiro abater $70 \%$ do IR, desde que invistam em projetos nacionais de produção de obras brasileiras.

\section{Medida Provisória nํㅜ 2.228-1}

Além de criar a Ancine, a MP criou quatro dispositivos de incentivos fiscais:

- isenção da contribuição para o desenvolvimento da indústria cinematográfica nacional (Condecine), taxação sobre os rendimentos decorrentes da exploração comercial da atividade audiovisual - permite isenção parcial a programadores estrangeiros que invistam em produção de obras brasileiras de produção independente, além de obras jornalísticas, esportivas, beneficentes, filantrópicas e político-partidárias;

- fundos de financiamento da indústria cinematográfica nacional (Funcines) - fundos de investimento constituídos pela venda de cotas ao público por instituições financeiras. Os recursos devem ser aplicados, com aprovação da Ancine, em projetos de obras nacionais independentes, construção e reforma de salas de exibição e aquisição de empresas no setor;

- Programa de Apoio ao Desenvolvimento do Cinema Nacional (Prodecine), em fase de regulamentação - recursos provenientes de percentual do Condecine, multas e juros recolhidos pela Ancine, remuneração de financiamentos diretos, doações e verbas orçamentárias, para aplicação em projetos de obras brasileiras de produção independente; 
- Lei $\mathrm{n}^{\mathrm{O}}$ 10.179/01 - conversão da dívida brasileira em projetos de produção, distribuição, exibição e divulgação de obras audiovisuais brasileiras.

Conforme levantamento realizado pelo TCU, a tabela discrimina os montantes no uso dos mecanismos fiscais de investimento no audiovisual, no período de 1995 a 2003:

\begin{tabular}{|c|c|c|c|c|c|c|c|c|c|c|}
\hline \multicolumn{11}{|c|}{$\begin{array}{l}\text { Investimentos em audiovisual por meio dos mecanismos fiscais: } \\
\qquad 1995-2003(\mathrm{R} \$ \mathrm{mil})\end{array}$} \\
\hline \multirow{2}{*}{ Mecanismo } & \multicolumn{9}{|c|}{ Ano } & \multirow{2}{*}{$\begin{array}{c}\text { Total } \\
1995- \\
2003\end{array}$} \\
\hline & 1995 & 1996 & 1997 & 1998 & 1999 & 2000 & 2001 & 2002 & 2003 & \\
\hline \multicolumn{11}{|l|}{ Lei do } \\
\hline Audiovisual & 20.292 & 58.052 & 79.456 & 43.093 & 39.797 & 33.406 & 56.713 & 45.852 & 58.554 & 435.215 \\
\hline 口 Certificados & 16.261 & 51.233 & 75.607 & 39.093 & 35.932 & 28.313 & 41.488 & 34.274 & 25.788 & 347.989 \\
\hline 口 Investimento & 4.031 & 6.819 & 3.848 & 4.000 & 3.865 & 5.093 & 15.225 & 11.578 & 32.766 & 87.225 \\
\hline Lei Rouanet & 8.056 & 17.499 & 34.160 & 30.088 & 19.604 & 22.426 & 43.981 & 20.030 & 11.802 & 207.646 \\
\hline $\begin{array}{l}\text { Conversão } \\
\text { da dívida }\end{array}$ & - & - & - & - & 953 & 5.506 & 540 & 3.192 & 2.180 & 12.371 \\
\hline $\begin{array}{l}\text { Isenção da } \\
\text { Condecine }\end{array}$ & - & - & - & - & - & - & - & - & 9.084 & 9.084 \\
\hline Total & 28.348 & 75.5511 & 113.615 & 73.181 & 60.354 & 61.3381 & 101.234 & 69.074 & 81.620 & 664.315 \\
\hline
\end{tabular}

口Verificamos que o montante disponibilizado pelos mecanismos de incentivo é afetado diretamente por momentos de instabilidade macroeconômica, como a "crise asiática" (1997/98), a desvalorização do real (1999/00) e a instabilidade do processo eleitoral (2002). Por outro lado, a consolidação da Lei do Audiovisual, a partir de 1996, garante um patamar mínimo de recursos, que vem sustentando uma quantidade relativamente estável de produção fílmica. Como a Ancine é implementada, na prática, apenas em meados de 2002, e considerando que houve uma recuperação da disponibilidade de recursos em 2003, apesar da recessão daquele ano; e, segundo informações preliminares colhidas no site da agência, também em 2004 (cerca de R\$ 100 milhões), pode-se estar configurando uma relação de variação direta da atuação da agência com este aumento de recursos de incentivo, o que terá que ser confirmado com dados dos anos posteriores. 
Em relação ao trabalho de fiscalização e normatização desenvolvido pela Ancine, de março de 2002 a dezembro de 2004 foram editadas 37 instruções normativas, 126 portarias, 20 resoluções da diretoria colegiada e cerca de 280 deliberações, versando sobre aprovação de projetos, autorização de captação de recursos com a comercialização de certificados de investimento, formalização de contratos de co-produção e doações e patrocínios.

Em seu site (www.ancine.gov.br), no início de 2005, a Ancine afirma (grifo nosso):

\begin{abstract}
Em seus três anos de existência, a Ancine implantou-se fisicamente, equipou-se com recursos humanos e infra-estrutura técnica, saneou e aperfeiçoou mecanismos de incentivos fiscais que movimentam cerca de $\mathrm{R} \$ 100$ milhões por ano, manteve a participação nos festivais internacionais, retomou a regulamentação no mercado e deu início à sua fiscalização, interrompida desde 1990. A Ancine desenvolveu o conceito de fomento regulador, e tem atualmente aberto seu sexto edital de apoio. Outros editais apoiaram o desenvolvimento de projetos, a produção, a finalização e a distribuição de obras cinematográficas. Está em fase final o planejamento estratégico da agência para 2005 e sua próxima prioridade é concluir o desenvolvimento da gestão de informação, para poder contribuir para o embasamento das políticas públicas desenhadas pelo Ministério da Cultura e pelo Conselho Superior de Cinema.
\end{abstract}

\title{
5. Ancinav
}

A atuação do governo Lula em relação ao debate sobre as agências reguladoras centrou-se na questão dos graus de autonomia e controle social. Uma das iniciativas do governo foi o envio de um projeto de lei ao Congresso, em abril de 2004, propondo maior uniformidade na estrutura, controle e responsabilização das agências existentes (Brasil, 2004a; Pacheco, 2004). Em relação ao cinema e ao audiovisual, propôs, ainda, uma iniciativa polêmica: a apresentação à sociedade da minuta de projeto de lei criando a Ancinav e extinguindo a Ancine.

Entre as áreas afetas à cultura, sob responsabilidade do governo federal, o cinema tem sido, desde a criação do Ministério da Cultura, nos anos 1980, o foco central e prioritário das políticas públicas e da destinação de verbas de fomento. A área é servida, atualmente, não apenas pela Lei Rouanet, mas por outra lei específica de benefícios fiscais, exclusiva para o audiovisual, além de outros mecanismos e fundos geridos pela Ancine. O esforço do governo atual em reestruturar o setor com o modelo proposto pelo projeto da Ancinav, busca alargar o escopo de atuação da agência, dando ao sentido de audiovisual preponderância em relação ao cinema. Em especial, busca-se fis- 
calizar e regular as atividades cinematográficas e audiovisuais realizadas por serviços de telecomunicações, radiodifusão e comunicação eletrônica de massa, TV a cabo, por assinatura, via satélite e multicanal, além de jogos eletrônicos, telefonia celular e internet que transmitam conteúdos audiovisuais.

Dados do Ministério da Cultura (Senna, 2004) apontam que 90\% dos filmes exibidos pela TV brasileira são produzidos nos EUA, menos de $10 \%$ da população brasileira freqüenta cinemas, cerca de $75 \%$ do mercado exibidor brasileiro estão ocupados por filmes norte-americanos e mais de $90 \%$ dos municípios brasileiros não possuem salas de cinema. Um dos objetivos da Ancinav é equilibrar as condições de participação da indústria cinematográfica e audiovisual nacional em relação à produção internacional e ao monopólio de empresas de produção e distribuição de massa, resguardando e protegendo, com mecanismos especiais, a diversidade e a competitividade do mercado setorial interno.

O projeto de remodelação da agência reforça, de um lado, o papel fomentador, reitera as poucas características estritamente regulatórias e reforça o padrão conceitual de agência executiva, não assumido pela Ancine. Por outro lado, porém, imprime uma intervenção mais abrangente na política pública, seja pela incorporação de segmentos de mercado audiovisual não "regulados" pela Ancine, seja pela descrição de valores e normas simbólicas, que a levam a diretrizes propriamente culturais, aproximando a agência de objetivos efetivamente sociais. A engenharia institucional que permeia essa nova amplitude de abordagem dá à agência uma capacidade de intervenção superior ao escopo regulatório, transformando-a no que chamarei de "agência articuladora de política pública setorial”.

Analisando a minuta do projeto de lei que propõe a criação da Ancinav, interpretamos a intenção de constituir uma agência não mais adstrita somente à questão do fomento econômico e à normatização de mercado, mas à implantação de um perfil que remete à escolha político-ideológica de ativismo em defesa da indústria audiovisual nacional, bem como de questões de valorização simbólica da cultura, tratando de conceitos como "brasilidade", direitos sociais, soberania, ética, diretrizes de política cultural como regionalização, descentralização, educação pela imagem e direitos do cidadão à fruição artística e cultural. Além disso, propõe uma ênfase mais ampla na dimensão do conceito e abrangência dos segmentos de mercado audiovisual e no combate à monopolização do setor audiovisual, notadamente no segmento das telecomunicações.

A seguir, destacamos proposições de temas que não estão presentes nos textos legais da Ancine, e que fazem parte das atribuições e do escopo da nova agência. 


\section{Regulação social}

\section{Valores e direitos culturais e sociais}

Garantir o desenvolvimento e preservação do patrimônio cultural e assegurar o direito de os brasileiros verem e produzirem sua imagem, fortalecendo a diversidade cultural; respeitar e proteger direitos fundamentais e valores éticos e sociais da pessoa e da família; promover informação, educação, cultura e lazer; direito à fruição de obras cinematográficas.

\section{Valores nacionalistas}

Promover e preservar a soberania e os valores brasileiros; harmonizar o setor com as metas de desenvolvimento do país.

\section{Regulação econômica}

\section{Mercado audiovisual}

Corrigir os efeitos da competição imperfeita e reprimir as infrações da ordem econômica; fiscalizar a aplicação de normas legais relativas à exploração de atividades cinematográficas e audiovisuais, inclusive por prestadores de serviços de telecomunicações; prevenir as infrações à ordem econômica; regular a relação de programadoras e distribuidoras, em especial onde haja controle pela mesma empresa.

\section{Criação de fundos}

Criar o Fundo de Fiscalização do Cinema e do Audiovisual (Fiscinav), com o intuito de cobrir despesas na execução e aperfeiçoamento da fiscalização pela agência, produto do próprio exercício de fiscalização (taxas, multas e indenizações).

Criar o Fundo Nacional para o Desenvolvimento do Cinema e do Audiovisual Brasileiros (Funcinav), cujo objetivo é fomentar as atividades audiovisuais e cinematográficas, capacitar recursos humanos, aperfeiçoar a infra-estrutura e ampliar a competitividade do setor. Seus recursos serão provenientes de dotação 
orçamentária, percentual da Condecine, aplicações financeiras, remuneração de financiamentos e doações. Cria os Programas de Apoio ao Desenvolvimento do Cinema e do Audiovisual Brasileiro e o Prêmio Adicional de Renda.

\section{Estrutura institucional e objetivos administrativos}

Atribuição do ministério supervisor (Cultura): responsabilizar-se pelo desenvolvimento e aplicação da política nacional do cinema e do audiovisual, formulando diretrizes e políticas públicas.

Atribuições da agência:

- "a articuladora de política pública setorial" - conexão de objetivos econômicos com valores sociais e políticos e integração administrativa setorial;

- integrar programática, econômica e financeiramente as atividades governamentais relacionadas ao cinema e ao audiovisual;

- propor ao Poder Executivo planos gerais de metas para a implementação de políticas públicas setoriais;

- criar o Sistema de Informações e Monitoramento das Atividades Cinematográficas e Audiovisuais, sistema de controle de receitas de bilheteria e relatórios sobre a oferta de obras cinematográficas.

\section{Controle e accountability}

As reuniões do conselho diretor (que substitui a diretoria colegiada, sem alteração profunda de atribuições) serão públicas e registradas em atas a serem divulgadas por meio da internet. A agência disponibilizará aos órgãos e entidades de defesa da concorrência informações sobre sua atuação, sempre que solicitada. Minutas dos atos normativos serão submetidas à consulta pública $\mathrm{e}$ devem permanecer à disposição do público.

Verificamos que o modelo da nova agência aprofunda o papel de órgão articulador de toda a política setorial, ainda mais se levarmos em conta que a agência deve contar com os quadros técnicos mais especializados na administração pública nesse setor. Num artigo fundamental da minuta (Brasil, 2004b), o texto é claro sobre a amplitude dos objetivos da agência e a integração dos âmbitos em que deve atuar:

Rap Rio de Janeiro 40(4):647-77, Jul./Ago. 2006 
na disciplina das relações econômicas, observar a soberania nacional, a diversidade e preservação do patrimônio cultural brasileiro, a função social da propriedade, a vedação ao monopólio e ao oligopólio dos meios de comunicação social, liberdade de iniciativa, livre concorrência, redução das desigualdades regionais e sociais e repressão ao abuso do poder econômico.

\title{
6. A polêmica
}

\section{Captura privada $\mathrm{x}$ intervencionismo estatal}

O debate polarizado que surge com a intenção, pelo governo Lula, de transformar a Ancine em Ancinav, surge de fortes pressões e críticas conduzidas contra o que se proclama "intervencionismo estatal": interferência na liberdade de criação e livre-iniciativa, ameaça à liberdade de imprensa, aumento da carga fiscal sobre o setor, por meio do aumento da base e alíquotas, o aparelhamento e aumento da estrutura burocrática da agência etc. Por outro lado, entusiastas da nova proposta defendem o novo modelo, contrapondo-o ao processo de centralização e captura privada pelo qual a Ancine teria passado, defendendo o projeto Ancinav em termos de democratização do acesso ao fomento e de defesa da cultura brasileira.

Analisando as negociações que conduziam o processo de formatação e apresentação da nova agência, Hamburger (2005) fala do

\begin{abstract}
processo de negociação espinhoso, mas aberto à manifestação dos mais diversos segmentos envolvidos. As pressões sobre a criação da Ancinav são imensas. Basta lembrar que a Ancine era Ancinav até a véspera da promulgação da medida provisória que a instituiu. A pressão das emissoras de TV levou à redução da agência ao âmbito do cinema.
\end{abstract}

O novo projeto novamente "confronta as arquipoderosas emissoras de TV" que utilizam o discurso pela "liberdade de expressão e livre-iniciativa". Fresnot (2004) aponta que

ao expor sua vontade de regular o conteúdo dos meios de comunicação e ao propor simultaneamente uma quantidade de taxas e contribuições sobre vários segmentos da atividade, gerou uma tão viva reação dos interesses contrariados que por pouco estes não derrubam toda a iniciativa. 
Os argumentos dos que apóiam a mudança (Aprocine, 2004) louvam

a volta do Estado brasileiro às suas responsabilidades constitucionais de mediador das questões econômicas ligadas à sobrevivência, ao desenvolvimento e ao saudável funcionamento de um setor produtivo de extrema importância para o futuro do país.

Deste lado, estão basicamente os novos diretores, produtores independentes e realizadores de regiões fora do eixo Rio-São Paulo. Entre os que se opõem à Ancinav, estão redes de exibição, distribuidores estrangeiros, redes de telecomunicação, grandes produtores e cineastas "consagrados" do eixo Rio-São Paulo. Organizados no Fórum do Audiovisual e do Cinema se voltam contra os riscos de partidarização, controle da produção artística e cultural, censura, centralismo, autoritarismo, imposição de conteúdo e desestímulo à livre-iniciativa que a nova agência traria. Segundo Jabor (2004),

este projeto do Minc ambiciona muito mais do que regular o cinema ou a TV (...) visa a controlar o pensamento, visa a um poder puro intocável, para uma infiltração na sociedade reflexiva, como uma tática "revolucionária". (...) pois a finalidade principal clara é colocar a TV Globo de joelhos, velho desejo totalitário.

Mas de onde vem esse viés crítico? Ao analisarmos a minuta do projeto de lei de criação da Ancinav, nos deparamos com: "Art. $2^{\underline{0}}$ A manifestação do pensamento, a criação, a expressão e a informação não sofrerão qualquer restrição ou censura de natureza política, ideológica e artística (...)" e "Art. 40 VI - salvaguardar a liberdade de expressão e a diversidade de fontes de informação". Além disso, a defesa da identidade e do patrimônio cultural, a liberdade de expressão e de informação, a coibição de monopólios dos meios de comunicação e o estímulo à regionalização, aos conteúdos educativos e à produção independente estão consagrados na Constituição Federal, em seus arts. 215, 216, 220 e 221. como:

Presume-se, talvez, que a oposição ao projeto se atenha a passagens

Art. 8oㅡ, Parágrafo único. O poder público, levando em conta os interesses do país no contexto de suas relações com os demais países, poderá estabelecer, mediante lei, limites à participação estrangeira no capital de exploradores de atividades cinematográficas e audiovisuais. 


\section{(...)}

Art. 42. A Ancinav disporá sobre a observância (...) dos seguintes princípios aplicáveis à produção e programação de conteúdos audiovisuais: I. preferência a finalidades educativas, artísticas, culturais e informativas; II. promoção da cultura nacional e regional e estímulo à produção independente; III. regionalização da produção cultural, artística e jornalística, conforme percentuais estabelecidos em lei; e IV. respeito aos valores éticos e sociais da pessoa e da família.

\section{(...)}

Art. 93. As prestadoras de serviços de radiodifusão de sons e imagens e outras (...) exploradoras de atividades audiovisuais estabelecerão anualmente um compromisso público, a ser firmado com a Ancinav e o Ministério da Cultura, para exibição de obras cinematográficas brasileiras de longa-metragem, obras (...) brasileiras destinadas ao público infantil e juvenil, bem como obras (...) brasileiras de produção independente e de produção regional (grifo do autor).

Observamos que o conteúdo extremado dos discursos polarizados não se reflete consistentemente no exame da letra da lei. A despeito das opiniões terem sido carregadas de viés ideológico e pouco refletirem uma análise racional mais balizada, louva-se o debate aberto e público, pela sociedade, em relação a escolhas de ferramentas institucionais adequadas, ainda mais envolvendo um setor de política pública - a cultura - geralmente relegado a segundo plano. Nota-se, contudo, que os discursos de ambos os lados são característicos da luta por benesses econômicas e da busca por influência sobre a máquina pública. Em outros termos, a mudança institucional, assim como qualquer política pública, remete à definição de ganhadores e perdedores nos mecanismos de alocação, e a troca de modelo de agência pressupõe a troca de guarda de interesses, com ganhadores e perdedores. "As políticas reguladoras, como todas as políticas públicas, têm conseqüências redistributivas" (Majone, 1999).

\section{Analisando experiências estrangeiras}

\section{Argentina}

O Instituto Nacional de Cinema e Artes Audiovisuais é um ente público nãoestatal, sob supervisão da Secretaria de Cultura da Presidência. Tem por encargo o fomento e a regulação da atividade cinematográfica. É dirigido por 
um presidente e seu vice, indicados pelo Poder Executivo, que presidem uma assembléia federal, composta por secretários de cultura de todas as províncias. A estrutura do instituto congrega, ainda, um conselho assessor, formado pela presidência do instituto, representantes da assembléia e das entidades e organizações privadas que atuam no setor.

O instituto administra o Fundo de Fomento Cinematográfico, custeado por taxas sobre a exibição e comercialização de produtos audiovisuais, fiscaliza o cumprimento de leis e normas e pode aplicar normas e sanções. Tem, assim, atribuições muito próximas às da Ancine, mas não está estruturado sobre um desenho institucional e formal de agência, com características de autonomia e fixação de mandatos. A Argentina, não obstante a crise econômica pela qual passou, vem apresentando recentemente bons resultados na produção e distribuição, inclusive ao exterior, de suas produções cinematográficas, seja em quantidade como em qualidade.

\section{México}

O México não possui um único órgão para gestão da indústria audiovisual. A Lei Federal de Cinematografia, que normatiza o setor, foi criada em 2001 e é aplicada por meio da administração direta: a Direção de Rádio, TV e Cinema da Secretaria de Governo da Presidência. Entre suas funções, destacam-se a regulação, a classificação dos filmes, a fiscalização do mercado e a aplicação de sanções.

O fomento à indústria cinematográfica fica a cargo do Fidecine, gestor do fundo de incentivo à produção, coordenado por um comitê técnico presidido por um representante do Instituto Mexicano de Cinema. O país apresenta, assim, um sistema misto que engloba atuação da administração direta e indireta, com institutos e fundos que visam ao fomento da produção. Assim como a Argentina, tem havido um interessante reerguimento da indústria cinematográfica no país.

\section{França}

O Estado francês tem uma tradição aguerrida de defesa da francofonia, dos valores e do patrimônio do que chamam de "civilização francesa". O país é vanguarda na defesa da "exceção cultural" (Casella, 2002), pela qual bens de valor simbólico e cultural devem ser preservados dos tratados de livre-comércio, e tratados como objetivos estratégicos dos Estados e nacionalidades. 
O principal órgão de regulação cultural francês é o Conselho Superior do Audiovisual. Criado por lei nos anos 1980, tem como foco a liberdade de comunicação e a defesa da cultura francesa. É dirigido por nove membros, indicados igualitariamente pela Presidência da República, pela Assembléia Nacional e pelo Senado. A Lei $\mathrm{n}^{\mathrm{o}} 86.087$ normatiza toda a área de cinema, rádio, TV aberta, a cabo e satélite, as comunicações e o jornalismo. Seus artigos são bastante específicos, chegando a minúcias em definições de normas e conceitos.

A direção do conselho tem mandato fixo e alternado de seis anos. O conselho tem obrigação de publicar suas deliberações e emitir relatórios para controle legislativo. Entre suas funções está a aplicação da lei executiva do audiovisual, a outorga, normatização, regulamentação, fiscalização, controle da programação, definição de cotas para a produção francesa e aplicação de sanções.

A forma e a função do conselho tornam-no muito semelhante a uma agência regulatória. Ele, na prática, aplica política de Estado, gera regulamentos e normas, responde ao poder eleito, tem autonomia e possui delegação de poder. Mais do que uma estrutura institucional, é a força da Loi no $06-1067 / 86$ que lhe dá legitimidade e delegação para agir como agência, mesmo sem sê-lo formalmente.

A produção francesa é a segunda em termos de exposição internacional e a única que tem uma proposta estratégica de disputa com o poderio americano. Tradicionalmente, a produção é considerada um baluarte da cultura francesa, já produziu filmes e cineastas com reconhecimento mundial.

\footnotetext{
Também há, na TV francesa, reserva de mercado para filmes europeus. Como os americanos têm na exportação de entretenimento um dos itens mais rentáveis de sua balança (...) a França foi muito clara no sentido de não escancarar suas fronteiras e de exigir um tempo mínimo para o cinema francês e/ou francês na sua TV.
}

(Ribeiro, 1998)

\section{Reino Unido}

Os britânicos criaram em 2000 a UK Film Council, uma nova organização estratégica para o desenvolvimento da indústria cinematográfica. Considerada uma empresa de direito privado, tem delegação governamental para estimular a cultura britânica e a competitividade da indústria cinematográfica. A empresa realça a importância do cinema como parte central das chamadas indústrias "criativas" britânicas, e movimenta um orçamento de 60 milhões de 
libras por ano, originados de financiamento direto do governo e da gestão de recursos de loterias.

Apesar do paradigma de "agencificação" da administração pública, o caso britânico apresenta uma solução de privatização da atribuição da gestão da política cinematográfica. Diferentemente da França, a indústria tem uma perspectiva mais de colaboração do que de enfrentamento com a produção norte-americana. Sua produção já foi bem mais importante em termos de quantidade e qualidade do que é hoje.

\section{Conclusões}

\section{Gênese da agência - hipóteses teóricas e contexto de criação}

\section{Hipóteses institucionais}

Analisaremos a gênese de um desenho institucional tão específico e peculiar como a Ancine, a partir do aporte teórico apresentado por Gilardi (2003). O autor analisa a tendência de criação de agências reguladoras na Europa utilizando referenciais teóricos que podem ser aplicados ao caso brasileiro. Partindo de paradigmas neo-institucionalistas, para os quais as trajetórias e influências do passado determinam o comportamento institucional dos atores no presente, Gilardi apresenta hipóteses explicativas à forte difusão de agências reguladoras independentes: "any pattern of successive adoptions of a policy innovation can be called diffusion".

Destacamos três hipóteses causais e conectadas entre si, que remetem à escolha pelo modelo de agência reguladora para o cinema:

- influência (symbolic diffusion) — os atores são influenciados pelo comportamento de outros atores, cujas escolhas prévias tendem a constranger as escolhas presentes, às vezes sem maiores avaliações quanto à eficácia do instrumento para a resolução de problemas. No Brasil, a experiência de quase-extinção do setor cinematográfico após a extinção traumática da Embrafilme pode ter influenciado a escolha de mecanismo mais estável e autônomo, criado por lei, já testado em setores essenciais do serviço público, e, portanto, menos passível de mudanças e interrupções abruptas; 
- adesão (spurious diffusion ou policy bandwagoning) — atores interdependentes tendem a reagir de forma similar a pressões similares. A busca de credibilidade e estabilidade intertemporal para garantir investimentos num setor em expansão, com a chegada de novos atores-investidores e a necessidade de desenvolvimento tecnológico, pode ter fomentado a pressão dos atores ("efeito ônibus") pela criação de um ambiente institucional mais seguro, com garantias perante as "incertezas da política";

- indução (isomorfismo institucional) — preenchimento do vácuo de gestão de política pública setorial por meio do mimetismo institucional, buscando a similaridade com os novos modelos organizacionais que o serviço público vinha criando no seu processo de reforma gerencial. Os atores tendem a repetir experiências reputadas como bem-sucedidas em outros espaços da administração pública. No caso, experiências que se processavam no próprio governo federal brasileiro.

De acordo com a literatura neo-institucionalista sociológica, as agências reguladoras independentes são consideradas como fatos dados, objetivos e consistentes, legitimados por escolhas anteriores de políticas públicas e pela presunção de sua maior eficácia. Além disso, no final da década de 1990, as ARs passam a constituir paradigma de reforma do Estado na América Latina, naquilo que Oszlack (1998) chama de segunda fase das reformas, quando "se procura passar de uma situação de menos Estado para uma situação de melhor Estado. Seus objetivos apontam mais na direção do aparato institucional do que na direção da sociedade" (Oszlack e Felder, 2000, grifo do autor).

\section{Hipótese da pressão setorial privada}

O contexto sociopolítico na época da criação da Ancine apresentava as seguintes características no setor:

- a entrada no setor audiovisual de novos e importantes atores - redes de telecomunicação de massa, telefonia celular, TV a cabo, investidores estrangeiros atuando em co-produções e acordos de distribuição etc.;

- o pleno funcionamento de leis de incentivo, especialmente para o cinema, passando a gerar maior disponibilidade de recursos, carreados pelo Estado a produtores privados; 
- a oportunidade de altos retornos financeiros, dado o modelo combinado de renúncia fiscal e participação societária na produção audiovisual; oportunidades de intermediação, vinculação de imagem de empresas a empreendimentos culturais, diminuição da carga fiscal de pessoas físicas e jurídicas, ganhos em publicidade e propaganda etc.;

- a criação de uma massa crítica, produzida por cineastas e intelectuais, dispostos a garantir a sustentabilidade da retomada da produção cinematográfica;

- a organização e mobilização de produtores, artistas distribuidores, com visibilidade na mídia e acesso a fontes de pressão sobre decisões políticas.

A incerteza política quanto à permanência de ferramentas institucionais estáveis e a emergência do setor de telecomunicações no investimento setorial, como o caso da Globo Filmes, além dos já existentes mecanismos de incentivo fiscal, levam a uma pressão pela constituição de um órgão gestor com as características de uma agência reguladora - credibilidade e estabilidade de um lado e possibilidade de captura, por outro, dado o que Thatcher (2002) chama de "systematic power of business". São consistentes os estudos que sugerem o risco de que os reguladores sejam capturados por interesses dos regulados. Agências de Estado podem ser capturadas mediante informação privilegiada, controle de procedimentos técnico-burocráticos e cotas desproporcionais de riqueza e poder (Oszlack, 1998).

A construção institucional passa a resultar, assim, da presença de "pressures, both formal and informal, exerted on organisations by other organisations upon which they depend (...), dominant actors, that, through power relations, can impose the adoption of policies and thus contribute to their diffusion" (Gilardi, 2003). Essa explicação está intimamente ligada à pressão de interesses econômicos, organizações e formadores de opinião, que, em meados dos anos 1990, com a retomada da produção cinematográfica a partir de mecanismos de renúncia fiscal, exerceram influência para a construção de uma organização que lhes garantisse estabilidade. Novos e poderosos agentes econômicos privados passam a atuar na arena setorial do cinema, sob a nova perspectiva do Estado regulador. Buscava-se mimetizar o papel que as agências já existentes possuíam em termos de credibilidade para investimento: "if actors are influenced by the behaviour of other actors independently from the problem-solving benefits (...), diffusion can be conceptualised as isomorphism and as symbolic imitation" (Gilardi, 2003). Nessa linha de raciocínio, também Silberman (1993) aponta:

once structural changes are adopted by significant organizations, they become legitimized. Once changes are adopted by some organizations, other organizations also adopt the changes in order to acquire the benefits of organizational legitimacy - even though such changes may bring no other organizational benefits. 
Procuramos demonstrar como o jogo de pressões e ação política de agentes setoriais, endógenos e exógenos ao Estado, determinaram o modelo de desenho institucional para gerir o audiovisual no Brasil. A partir de características e contextos particulares, acreditamos que a gênese da agência resulta da ação interconectada e concomitante das hipóteses antes apresentadas.

\section{Agência regulatória $x$ agência executiva}

Outro ponto que analisamos é o caráter institucional da agência: possui perfil de agência executiva e não de agência reguladora. Esta última é conceitualmente referida à regulamentação de mercados com características monopolísticas, intertemporais e de atividades essenciais e típicas de Estado. Lida, inclusive, com determinação e revisão de preços e tarifas, controle de serviços e defesa do consumidor. As agências executivas, por seu lado, são delegações do Poder Executivo, com flexibilidade de gestão, que buscam implementar políticas públicas setoriais, fiscalizar e regular segmentos de mercado não-essenciais e arrecadar taxas (Bresser-Pereira, 1998). Este modelo está mais próximo do perfil institucional da Ancine e da Ancinav, mas não há qualquer menção a esses fatos nos textos legais e pronunciamentos oficiais sobre essas agências.

Segundo o Plano Diretor de Reforma do Aparelho do Estado, o formato mais adequado para as entidades voltadas à fiscalização e ao fomento seria o das agências executivas, inspiradas na experiência inglesa das agencies. Suas atribuições implicam o exercício de realização de políticas de governo (BresserPereira, 1997), o que justifica sua manutenção como "atividades exclusivas de Estado", não devendo ser repassadas ao setor privado nem ao setor público nãoestatal (Brasil, 1995). Além disso, agências executivas não precisam ser criadas por lei, podendo ser qualificadas pelo Poder Executivo por meio de contratos de gestão, que lhes daria maior flexibilidade, mas, talvez, menor estabilidade. A Lei Geral das Agências Reguladoras (Brasil, 2004b), em trâmite no Congresso Nacional, mantém o status de agência reguladora à Ancine e homogeneiza suas atribuições em relação às outras agências reguladoras brasileiras.

\section{Organização administrativa da agência}

O desenho institucional organizado a partir da criação da Ancine está submetido à supervisão formal do Ministério da Cultura e tem como órgão formulador de diretrizes de políticas públicas o Conselho Superior de Cinema, composto por sete ministros de Estado e cinco representantes da indústria. O conselho define a política nacional de cinema e estabelece as diretrizes para o seu desenvolvimento. A agência mantém - tanto quanto no modelo Ancinav - as características definidoras de agência independente, tais como: autonomia administrativa e financeira, ausência de subordinação hierárquica, mandatos fixos não-coinciden- 
tes e estabilidade dos dirigentes, cumprindo algumas atribuições regulatórias stricto sensu: regular atividades econômicas, assegurar direitos dos consumidores, expedir normas, fiscalizar e aplicar sanções.

Na prática, porém, conforme podemos observar na figura 2 , o sistema é centrado na ação executiva da agência reguladora. A política nacional de cinema depende da capacidade de gerenciamento da Ancine, que administra recursos, fiscaliza e normatiza o mercado, além de dar todo o suporte técnico ao setor. Há, dessa maneira, um déficit de governança estratégica por parte da administração direta e uma ênfase nas ações executivas da agência quanto à alocação de recursos oriundos de renúncia fiscal. Na ausência efetiva de um núcleo superior para definições de políticas estratégicas, cabe à agência o monitoramento quase exclusivo do setor.

Figura 2

\section{Desenho institucional do sistema}

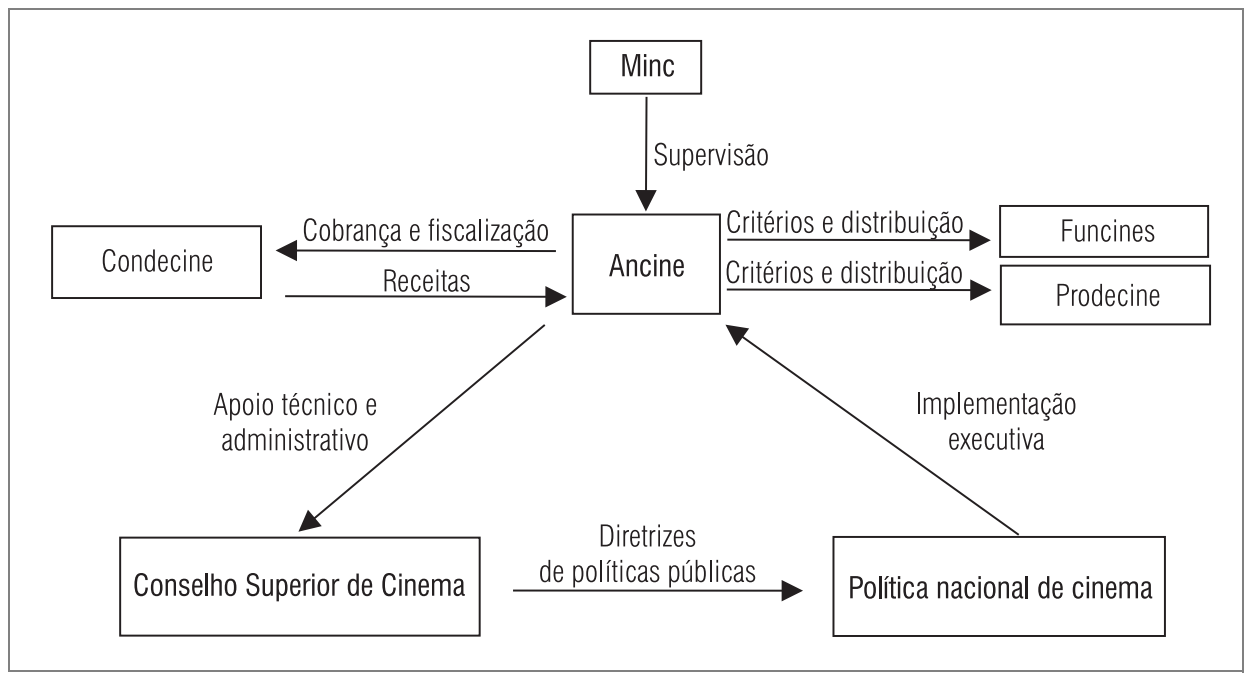

\section{Agência articuladora de política pública setorial}

A tendência da agência, que não é regulatória, mas de fomento (Pacheco, 2004), é tornar-se, especialmente com a reestruturação proposta com a Ancinav, um órgão indutor e articulador de política pública setorial. O Estado brasileiro pode estar aportando, assim, um novo e original desenho institucional, 
que confere à organização "agência" um papel de gerenciador de diretrizes setoriais, indo além da alocação de recursos, fomento à produção, fiscalização e regulação. Acrescem ao seu escopo características de definição de valores simbólicos e ideológicos e de integração administrativa das ações e dos agentes públicos e privados.

Nesse sentido, avaliamos que, se tomarmos a existência da agência como fato dado, e sem perspectivas de alteração, dada a configuração política do setor e sua relação com o poder, o modelo Ancinav tem o mérito de assumir a gestão do setor de uma forma mais ampla, buscando dar eficácia e sustentabilidade de política pública ao que poderia se tornar apenas gerenciamento de recursos alocados segundo interesses privados. Vai além do formalismo técnico normativo ao propor características propriamente culturais e valorativas, mais próximas das necessidades do setor e da especificidade social da cultura. Procura, ainda, integrar o planejamento, formulação e implantação da política pública do audiovisual, funcionando, na prática, como braço especializado e suporte técnico do ministério supervisor: de gestor de leis de incentivo à agência articuladora de política pública setorial.

\section{Referências bibliográficas}

ABRANCHES, S. H. H. Reforma regulatória: conceitos, experiências e recomendações. Revista do Serviço Público, Brasília: Enap, v. 2, n. 50, 1999.

AGÊNCIA NACIONAL DO CINEMA (ANCINE). Relatórios de gestão de 2002, 2003 e 2004. Disponíveis em: $<$ www.ancine.gov.br $>$.

ASSOCIAÇÃO BRASILEIRA DE ROTEIRISTAS (ARTV). Debate sobre a criação da Ancinav. Disponível em: <www.artv.art.br>. Acesso em: 6 jun. 2005.

APROCINE (ASSOCIAÇÃO DOS PRODUTORES E REALIZADORES DE LONGA-METRAGEM DE BRASÍLIA). Manifesto em defesa da Ancinav contra a tentativa golpista do FAC. 17 dez. 2004.

BRASIL. Constituição da República Federativa do Brasil. São Paulo: Imprensa Oficial, 2001a.

Medida Provisória n. 2228-1, de 6 de setembro de 2001. Estabelece princípios gerais da Política Nacional de Cinema, cria o Conselho Superior de Cinema, a Agência Nacional do Cinema - Ancine, institui o Programa de Apoio ao Desenvolvimento do Cinema Nacional — Prodecine, autoriza a criação de Fundos de Financiamento da Indústria Cinematográfica Nacional - Funcines e altera a legislação sobre a Contribuição para o Desenvolvimento da Indústria Cinematográfica Nacional. 2001b. Disponível em: <www.mj.gov.br/sistemas/sal/Txt Integral.asp?pMep=2228-1 ou <www.senado.gov.br/web/cegraf/pdf/20102004/32481.pdf> . 
Lei Geral das Agências Reguladoras. Minuta do Projeto de Lei n. 3.337/04, que dispõe sobre as regras aplicáveis às agências reguladoras, relativamente à sua gestão, organização e mecanismos de controle social. 2004a. Disponível em: <www.camara.gov.br>.

- Minuta do projeto de lei que dispõe sobre a organização de atividades cinematográficas e audiovisuais, sobre o Conselho Superior de Cinema e do Audiovisual e sobre a criação da Agência Nacional do Audiovisual. 2004b. Disponível em: <www.cultura.gov.br> .

BRASIL. Ministério da Administração Federal e Reforma do Estado (Mare). Plano diretor da reforma do aparelho do Estado. Brasília: Presidência da República, 1995.

. Tribunal de Contas da União. Relatório do TCU — auditoria realizada na Agência Nacional de Cinema - Ancine, com o objetivo de verificar os controles exercidos em projetos amparados pelas leis de incentivo à cultura. Ata n. 39, 20 out. 2004. Disponível em $<$ www.tcu.gov.br>. Acesso em: 8 jun. 2005.

Senado Federal. Constituição da República Federativa do Brasil. Título III — Da Ordem Social: capítulo VII — seção II — Da Cultura, arts. 215 e 216 e capítulo V — Da Comunicação Social, arts. 220 a 224. 1988.

BRESSER-PEREIRA, L. C. A reforma do Estado dos anos 90: lógica e mecanismos de controle. Brasília, Cadernos Mare, v. 1, 1997.

Reforma do Estado para a cidadania - a reforma gerencial brasileira na perspectiva internacional. São Paulo: Ed. 34; Brasília: Enap, 1998.

Sociedade civil: sua democratização para a reforma do Estado. In: ; WILHEIM, J.; SOLA, L. (Orgs.). Sociedade e Estado em transformação. São Paulo: Unesp, 2001.

CASELLA, P. B. Exceção cultural à livre circulação de bens e serviços: o ponto de vista do Brasil no Mercosul. Revista de Direito da USP, n. 97, 2002.

COTA de tela abre polêmica entre exibidores e Ancine. Folha de S. Paulo, 8 abr. 2005.

FARIAS, P. C. L. de. Regulação e modelo de gestão. In: NASSUNO, M.; KAMADA, P. (Orgs.). Balanço da reforma do Estado. Brasília: Seges-MP, 2002.

FRESNOT, A. L’Ancinav vá? Gazeta Mercantil, Rio de Janeiro, 17 dez. 2004.

GILARDI, F. Spurious and symbolic diffusion of independent regulatory agencies in Western Europe. In: THE INTERNATIONALIZATION OF REGULATORY REFORMS. University of California, Berkeley, 2003.

GOVERNO anuncia rumos da Ancinav. Folha de S. Paulo, 31 mar. 2005.

HAMBURGER, E. Análise especial. Folha de S. Paulo, São Paulo, 19 jan. 2005.

JABOR, A. Lei Cultural: Gil será responsável. O Estado de S. Paulo, São Paulo, 31 dez. 2004.

RaP Rio de Janeiro 40(4):647-77, Jul./Ago. 2006 
MAJONE, G. Do Estado positivo ao Estado regulador: causas e conseqüências de mudanças no modo de governança. Revista do Serviço Público, Brasília, v. 1, n. 50, 1999.

MELO, M. A. B. C. Política regulatória: uma revisão da literatura. Revista Brasileira de Informação Bibliográfica em Ciências Sociais, n. 50, 2000.

A política da ação regulatória: responsabilização, credibilidade e delegação. Revista Brasileira de Ciências Sociais, v. 16, n. 46, 2001.

OSZLAK, O. Estado e sociedade: novas regras de jogo? In: DINES, A. et al. Sociedade e Estado superando fronteiras. São Paulo: Fundap, 1998.

; FELDER, R. A capacidade de regulação estatal na Argentina. Revista do Serviço Público, v. 51, n. 1, 2000.

PACHECO, R. S. Agências reguladoras na infra-estrutura e na área social no Brasil: gênese e indistinções. In: ENCONTRO ANUAL DA ANPOCS, 28. Anais... Caxambu, 2004.

POWELL, W.; DIMAGGIO, P. The iron cage revisited: institutional isomorphism and collective rationality in organizational fields. In: The new institutionalism in organizational analysis. Chicago: The University of Chicago Press, 1991.

RAMOS, J. M. Cinema e lutas culturais. Rio de Janeiro: Paz e Terra, 1983.

RIBEIRO, R. J. et al. Marketing cultural: um investimento com qualidade. São Paulo: Informações Culturais, 1998.

SALGADO, L. H. Agências reguladoras na experiência brasileira: um panorama atual do desenho institucional. 2003. (Texto para Discussão Ipea, n. 941).

SENNA, O. Ancinav: autoritarismo ou democracia? O Povo, Rio de Janeiro, 18 dez. 2004.

SILBERMAN, B. S. Cages of reason. Chicago: The University of Chicago Press, 1993.

SIMIS, A. Estado e cinema no Brasil. São Paulo: Annablume/Fapesp, 1996.

TELA VIVA NEWS. Evento do FAC ataca Ancinav e Gilberto Gil. 15 dez. 2004.

THATCHER, M. Regulation after delegation: independent regulatory agencies in Europe. Journal of European Public Policy, v. 9, n. 6, 2002. 